\title{
The Effects of Eribulin on Breast Cancer Microenvironment Identified Using Eribulin-resistant Breast Cancer Cell Lines
}

\author{
WATARU GOTO ${ }^{1}$, SHINICHIRO KASHIWAGI ${ }^{1}$, YUKA ASANO $^{1}$, KOJI TAKADA $^{1}$, \\ KATSUYUKI TAKAHASHI ${ }^{2}$, HISAKAZU FUJITA ${ }^{3}$, TSUTOMU TAKASHIMA ${ }^{1}$, MASATSUNE SHIBUTANI ${ }^{4}$, \\ RYOSUKE AMANO ${ }^{5}$, SHUHEI TOMITA ${ }^{2}$, KOSEI HIRAKAWA ${ }^{1,4}$ and MASAICHI OHIRA ${ }^{1,4}$ \\ ${ }^{1}$ Department of Breast and Endocrine Surgery, Osaka City University Graduate School of Medicine, Osaka, Japan; \\ ${ }^{2}$ Department of Pharmacology, Osaka City University Graduate School of Medicine, Osaka, Japan; \\ ${ }^{3}$ Department of Scientific and Linguistic Fundamentals of Nursing, \\ Osaka City University Graduate School of Nursing, Osaka, Japan; \\ ${ }^{4}$ Department of Gastrointestinal Surgery, Osaka City University Graduate School of Medicine, Osaka, Japan; \\ ${ }^{5}$ Department of Hepato-Biliary-Pancreatic Surgery, Osaka City University Graduate School of Medicine, Osaka, Japan
}

\begin{abstract}
Background/Aim: Eribulin is currently used to treat advanced and metastatic breast cancer in the clinical setting; however, its efficacy is inhibited by resistance acquisition in many cases. Thus, the present study established two eribulinresistant breast-cancer cell lines, and used these to investigate the mechanisms that underly eribulin-resistance acquisition. Materials and Methods: Eribulin-resistant breast-cancer cell lines were generated by culturing MDA-MB-231 and MCF-7 cells with increasing concentrations of eribulin. Results: The eribulin-resistant cells acquired resistance to eribulin, as well as several other anticancer drugs. After eribulin treatment, the eribulin-resistant cell lines showed no morphological change, no increased expression of epithelial-cadherin, nor any significant alteration in cell-cycle distribution. In contrast, the expression levels of programmed death-ligand 1 were increased in the MCF-7/eribulin-resistant compared to MCF-7 cells. Conclusion: The herein developed eribulin-resistant cell lines acquired cross-resistance to various anticancer agents, and displayed resistance to eribulin-induced effects on microtubule function and epithelial-mesenchymal transition (EMT).
\end{abstract}

Eribulin is a non-taxane, synthetic microtubule-dynamics inhibitor that binds microtubule ends to prevent microtubule

This article is freely accessible online.

Correspondence to: Shinichiro Kashiwagi, MD, Ph.D., Department of Breast and Endocrine Surgery, Osaka City University Graduate School of Medicine, 1-4-3 Asahi-machi, Abeno-ku, Osaka 5458585, Japan. Tel: +81 666453838, Fax: +81 666466450, e-mail: spqv9ke9@view.ocn.ne.jp

Key Words: Eribulin, microenvironment, epithelial-mesenchymal transition, breast cancer, resistance. polymerization, and thereby induces $\mathrm{G}_{2} / \mathrm{M}$ cell-cycle arrest, and subsequent cell death by apoptosis (1-3). It is currently an approved treatment for patients with locally advanced or metastatic breast cancer (MBC), since it was previously shown by a phase-III trial (study 305/EMBRACE) to significantly improve the overall survival (OS) of patients with MBC who had previously been administered chemotherapy, including with an anthracycline and a taxane drug (4). Interestingly, eribulin has been reported to exert some unique anticancer effects; for example, a previous study by Funahashi et al. suggested that eribulin treatment improves tumor perfusion in breast cancer, and ameliorates tumor hypoxic stress (5), while another by Yoshida et al. revealed that eribulin suppresses epithelial-mesenchymal transition (EMT) in breast-cancer cells (6). We previously investigated and confirmed these effects using clinical tumor samples (7), and moreover, showed that eribulin enhances the antitumor immune response by improving the immune tumor microenvironment (8).

Nevertheless, most breast-cancer cells eventually acquire resistance to eribulin. Chemotherapy-resistance acquisition is often associated with hypoxia or $\operatorname{EMT}(9,10)$; however, since eribulin is known to ameliorate these phenomena in the tumor microenvironment, the precise mechanism underlying eribulin-resistance acquisition has not yet been elucidated. Thus, the present study examined this mechanism by establishing, and investigating the biological characteristics of two eribulin-resistant cell lines from standard human breast-cancer cell lines.

\section{Materials and Methods}

Cell lines and culture conditions. Two human breast-cancer cell lines (MDA-MB-231 and MCF-7) were purchased from the American Type Culture Collection (ATCC; Rockville, MD, USA), and cultured $\left(37.0^{\circ} \mathrm{C}, 5 \% \mathrm{CO}_{2}\right.$, in a humidified chamber) in 
Dulbecco's Modified Eagles Medium (DMEM; Wako, Osaka, Japan) that was supplemented with $10 \%$ fetal bovine serum (FBS; Equitech-Bio, Kerrville, TX, USA), $100 \mu \mathrm{g} / \mathrm{ml}$ streptomycin, and $100 \mathrm{U} / \mathrm{ml}$ penicillin (Gibco, Grand Island, NE, USA). The culture medium was replaced every 3 days.

Establishment of eribulin-resistant cell lines. Eribulin-resistant cell lines, comprising MDA-MB-231/eribulin-resistant (E) and MCF7/E, were established from the MDA-MB-231 and MCF-7 cells, respectively, via continuous exposure to increasing concentrations of eribulin (Eisai Co., Ltd., Tokyo, Japan). Specifically, the cells were exposed to an initial eribulin concentration of $0.2 \mathrm{nmol} / 1$, and this concentration was increased by a factor of 1.5 upon resistance acquisition (minimum time, $2 \mathrm{wks}$ ), until a final concentration of $131.4 \mathrm{nmol} / \mathrm{l}$ was reached.

Chemosensitivity assay. The sensitivity of the eribulin-resistant cell lines to various drugs was evaluated using a cell proliferation assay kit (MTT) (Sigma-Aldrich, St Louis, MO, USA), according to the manufacturer's instructions. Briefly, cells $\left(1 \times 10^{3}\right.$ cells/well in a 96well plate) were cultured $(24 \mathrm{~h})$ in $90 \mu \mathrm{l}$ of DMEM that was supplemented with $10 \%$ FBS. A $10 \mu$ laliquot of medium containing a graded concentration of eribulin, as well as paclitaxel (PTX; BristolMyers Squibb Co., NY, USA), vinorelbine (VNB), 5-fluorouracil (5-FU; Kyowa Hakko Kirin Co., Ltd., Tokyo, Japan), gemcitabine (GEM; Eli Lilly \& Co., IN, USA), or cisplatin (CDDP; Pfizer Inc., NY, USA), was then added to each well. After incubation for $72 \mathrm{~h}$, $10 \mu \mathrm{l}$ of the MTT regent was added to each well. After an additional $2 \mathrm{~h}$ incubation, the supernatant was discarded, and $100 \mu \mathrm{l}$ of dimethyl sulfoxide was added to each well. After shaking for $10 \mathrm{~min}$, the absorbance of each well was measured at $510 \mathrm{~nm}$ using a microplate reader (Perkin-Elmer, MA, USA), and the cell viability was determined. All samples were analyzed at least three times.

Analysis of cell-cycle progression. Cancer cells were seeded $\left(1 \times 10^{6}\right.$ cells/well) into six-well tissue culture plates. After $24 \mathrm{~h}$, the cells were harvested and washed twice with phosphate-buffered saline (PBS), before being stained using the CycleTESTTM PLUS DNA Reagent Kit (Becton Dickinson Biosciences, CA, USA), according to the manufacturer's instructions. The resultant staining was analyzed using BD LSR II flow cytometry FACSDiva ${ }^{\mathrm{TM}}$ software (Becton Dickinson Biosciences, CA, USA).

Western blot analysis. Proteins were extracted from cancer cells using PRO-PREPTM extraction solution (iNtRON Biotechnology, Seongnam, South Korea). The resultant lysates were separated via sodium dodecyl sulfate-polyacrylamide gel electrophoresis, and protein bands were transferred to polyvinylidene difluoride membrane using the Trans-Blot Turbo ${ }^{\mathrm{TM}}$ Transfer System (Bio-Rad, Hercules, CA, USA). After blocking, the membranes were probed with antimicrotubule-end-binding 1 (EB1) (1:1,000; Bethyl laboratories, TX, USA), and anti-multi-drug resistance 1/ATP binding cassette subfamily B member 1 (MDR1/ABCB1) $(1: 1,000$; Cell Signaling Technology, MA, USA) antibodies. $\beta$-actin $(1: 1,000$; Cell Signaling Technology, MA, USA) was used as a loading control. Membranebound primary antibodies were detected using horseradish peroxidase-conjugated anti-mouse or anti-rabbit immunoglobin-G secondary antibodies (GE healthcare, Buckinghamsire, UK), and protein bands were visualized using the Luminescent Image Analyzer LAS 4000-plus (Fuji Film, Tokyo, Japan).
Quantitative real-time-polymerase chain reaction ( $q R T-P C R)$. The total RNA from cultured cells was extracted using the RNeasy Mini kit (Qiagen, CA, USA). Relevant cDNA was amplified via qRTPCR using Taq DNA polymerase (Nippon Gene, Tokyo, Japan), the StepOnePlus RT-PCR system (Applied Biosystems, CA, USA), and TaqMan gene expression assays for epithelial cadherin ( $\mathrm{CDH1}$; assay ID, Hs01023894), cluster of differentiation 274 (CD274; assay ID, Hs01125301), and glyceraldehyde 3-phosphate dehydrogenase (GAPDH; assay ID, Hs02758991) (Applied Biosystems, MA, USA). RT-PCR was carried out at $95^{\circ} \mathrm{C}$ for $15 \mathrm{sec}$, followed by 40 cycles of $60^{\circ} \mathrm{C}$ for $60 \mathrm{sec}$.

In vivo tumor model. In vivo experiments were carried out on 4-week-old female athymic BALB/c nu/nu mice (CLEA Japan, Tolyo, Japan), using a protocol that was approved by the Osaka City University Ethical Committee, Osaka, Japan. The mice were housed in a standard animal laboratory, and provided ad libitum access to food and water. MDA-MB-231 and MDA-MB-231/E (10×106 cells) were injected into the backs of the mice to produce subcutaneous xenografts, and the volumes (length $\times$ width) of the resultant tumors were measured weekly. All mice were sacrificed on day 21 after inoculation. Selected tissue sections were fixed in $10 \%$ neutral buffered formalin solution, and subjected to immunohistochemical staining.

Statistical analysis. Statistical analyses were performed using JMP13 software (SAS Institute, Cary, NC, USA). Comparisons between groups were made using a student's $t$-test. A $p$-value $<0.05$ was considered to indicate statistical significance.

\section{Results}

Effect of eribulin treatment on cancer-cell morphology. MDAMB-231/E and MCF-7/E cell lines were established via the continuous exposure of MDA-MB-231 and MCF-7 cells, respectively, to increasing concentrations $(0.2-131.4 \mathrm{nmol} / \mathrm{l})$ of eribulin. They were then subjected to various assays to assess their biological characteristics.

Initially, the MDA-MB-231 cells exhibited a spindleshaped phenotype; however, after eribulin treatment, surviving MDA-MB-231 cells instead displayed an epithelial-like cuboidal-shaped phenotype. In contrast, the MDA-MB-231/E cells exhibited a spindle-shaped phenotype both before and after eribulin treatment, and likewise, the phenotypes of both the MCF-7 and MCF-7/E cells were unchanged after eribulin treatment (Figure 1).

Sensitivity of parental and eribulin-resistant breast-cancer cells to eribulin. The sensitivity of the parental and eribulinresistant cells to eribulin was evaluated via an MTT assay, which revealed half maximal inhibitory concentration 50 $\left(\mathrm{IC}_{50}\right)$ values of $1.3,30.60 .1$, and $0.3 \mathrm{nmol} / 1$ for the MDAMB-231, MDA-MB-231/E, MCF-7, and MCF-7/E cells, respectively. Thus, each eribulin-resistant cell line exhibited a higher level of resistance to eribulin than its parental cell line (Figure 2). 

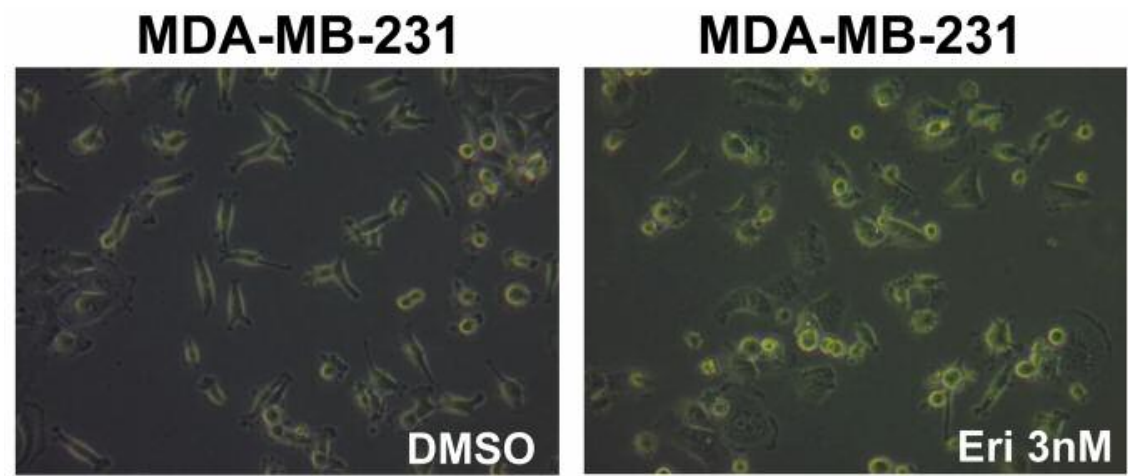

MDA-MB-231/E

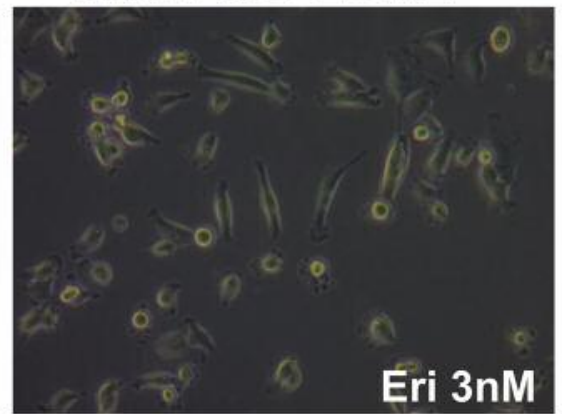

MCF-7

MCF-7

MCF-7/E
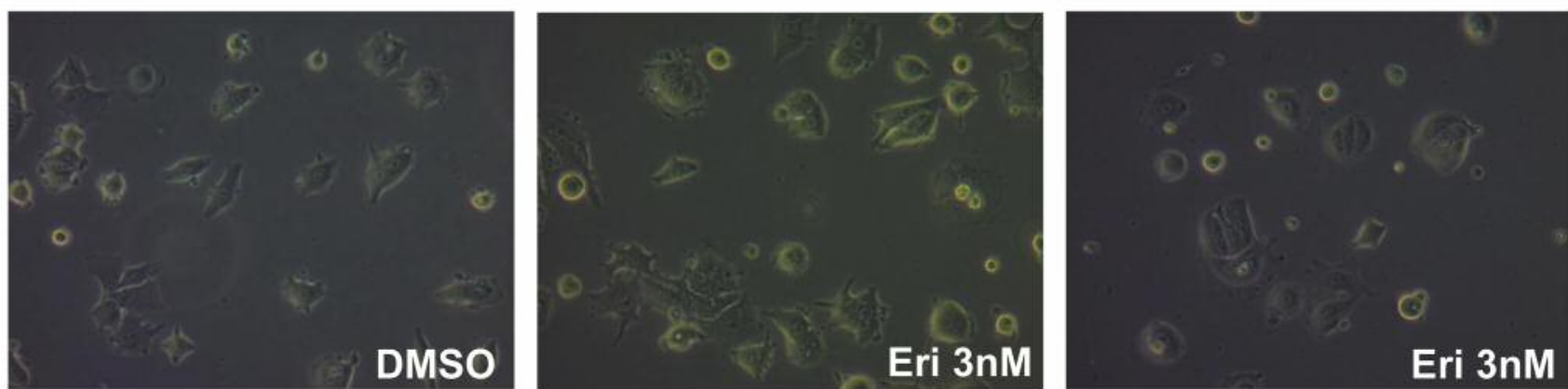

Figure 1. Representative images of MDA-MB-231, MDA-MB-231/E, MCF-7, MCF-7/E following treatment with eribulin. The MDA-MB-231 cells exhibited a spindle-shaped phenotype; however, after eribulin treatment, surviving MDA-MB-231 cells instead displayed an epithelial-like cuboidalshaped phenotype. In contrast, the MDA-MB-231/E cells exhibited a spindle-shaped phenotype both before and after eribulin treatment, and likewise, the phenotypes of both the MCF-7 and MCF-7/E cells were unchanged after eribulin treatment. E: Eribulin-resistant.

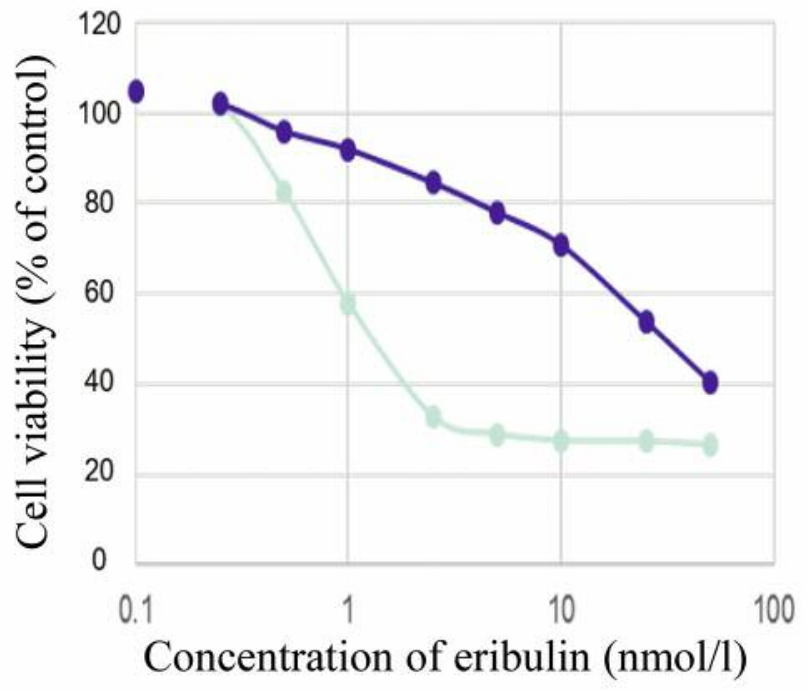

MDA-MB-231 MDA-MB-231/E

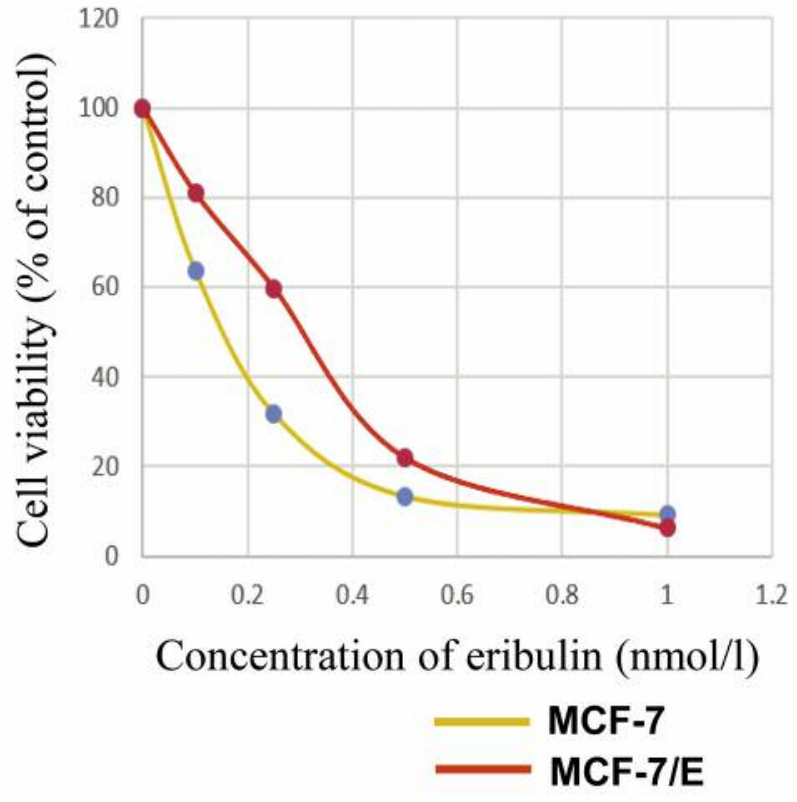

Figure 2. Dose-response curves of MDA-MB-231, MDA-MB-231/E, MCF-7 and MCF-7/E to eribulin. The sensitivity of the parental and eribulinresistant cells to eribulin was evaluated via an MTT assay, which revealed half-maximal inhibitory concentration 50 (IC 50$)$ values of 1.3, 30.6 0.1, and $0.3 \mathrm{nmol} / \mathrm{l}$ for the MDA-MB-231, MDA-MB-231/E, MCF-7, and MCF-7/E cells, respectively. E: Eribulin-resistant. 
Table I. Dose-response curve of MDA-MB-231, MDA-MB-231/E to paclitaxel, vinorelbine, gemcitabine, 5-FU and cisplatin.

\begin{tabular}{|c|c|c|c|c|c|c|c|c|c|c|c|c|}
\hline & \multicolumn{2}{|c|}{ Eribulin } & \multicolumn{2}{|c|}{ Paclitaxel } & \multicolumn{2}{|c|}{ Vinorelbine } & \multicolumn{2}{|c|}{ Gemcitabine } & \multicolumn{2}{|c|}{$5-\mathrm{FU}$} & \multicolumn{2}{|c|}{ Cisplatin } \\
\hline & $\begin{array}{c}\mathrm{IC}_{50} \\
(\mathrm{nmol} / \mathrm{l})\end{array}$ & RI & $\begin{array}{c}\mathrm{IC}_{50} \\
(\mathrm{nmol} / \mathrm{l})\end{array}$ & RI & $\begin{array}{c}\mathrm{IC}_{50} \\
(\mathrm{nmol} / \mathrm{l})\end{array}$ & RI & $\begin{array}{c}\mathrm{IC}_{50} \\
(\mathrm{pmol} / \mathrm{l})\end{array}$ & RI & $\begin{array}{c}\mathrm{IC}_{50} \\
(\mu \mathrm{mol} / \mathrm{l})\end{array}$ & RI & $\begin{array}{c}\mathrm{IC}_{50} \\
(\mu \mathrm{mol} / \mathrm{l})\end{array}$ & RI \\
\hline MDA-MB-231 & 1.3 & 23.5 & 4.0 & 7.3 & 25.2 & 3.5 & 4.5 & 0.7 & 27.3 & 1.4 & 52.8 & 0.6 \\
\hline MDA-MB-231/E & 30.6 & & 29.2 & & 87.6 & & 3.2 & & 39.1 & & 33.0 & \\
\hline MCF-7 & 0.1 & 3.0 & 2.9 & 3.7 & 2.1 & 3.7 & 2.9 & 1.0 & 0.5 & 5.8 & 0.3 & 2.0 \\
\hline MCF-7/E & 0.3 & & 10.7 & & 7.8 & & 2.8 & & 2.9 & & 0.6 & \\
\hline
\end{tabular}

E: Eribulin-resistant; $\mathrm{IC}_{50}$ : inhibitory concentration 50; RI: resistance index.

Cross-resistance of the eribulin-resistant breast-cancer cell lines to other drugs. Generally, cells resistant to one drug also acquire resistance to several other anticancer drugs (11); therefore, we examined whether the MDA-MB-231/E and MCF-7/E acquired cross-resistance to PTX, VNB, GEM, 5-FU, and/or CDDP (Figure 3) (Table I). By analyzing the calculated dose-responsive curves and $\mathrm{IC}_{50}$ values for these drugs, the MDA-MB-231/E cells were found to be crossresistant to PTX and VNB, but to remain sensitive to GEM, 5-FU, and CDDP. Conversely, the MCF-7/E cells acquired cross-resistance to PTX, VNB, 5-FU, and CDDP, but retained their sensitivity to GEM.

Cell-cycle progression in the parental and eribulin-resistant cancer cells. A flow-cytometric cell-cycle assay was performed to investigate the effect of eribulin on cell-cycle progression in the MDA-MB-231 and MDA-MB-231/E cells. The results of this analysis showed that the proportions of MDA-MB-231 cells that were in $\mathrm{G}_{2} / \mathrm{M}$ and $\mathrm{G}_{0} / \mathrm{G}_{1}$ phase were significantly increased and decreased, respectively, after eribulin treatment. In contrast, the proportions of MDA-MB231/E cells that were observed in each cell-cycle phase were not significantly altered after eribulin treatment (Figure 4).

Effects of eribulin treatment on protein expression in the parental and eribulin-resistant cancer cells. Although the expression of microtubule end-binding protein 1 (EB1) was decreased after eribulin treatment in the MDA-MB-231 cells, it was not altered by eribulin treatment in the MDA-MB231/E cells (Figure 5). In contrast, EB1 expression was decreased in both the MCF-7 cells and MCF-7/E cells after eribulin treatment. According to previous studies, ATPbinding cassette (ABC)-family proteins such as MDR1 are associated with multiple-drug resistance in breast cancer (12, 13); therefore, we examined the MDR1 expression in the parental and eribulin-resistant breast-cancer cell lines via western blot analysis. The results of this analysis showed no MDR1 expression in the eribulin-resistant cell lines.
CDH1 and CD274 mRNA expression in the parental and eribulin-resistant cancer cells. The total RNA was extracted from surviving parental breast cancer cells treated with eribulin for three days and eribulin-resistant cells, and was assayed via qRT-PCR. Notably, eribulin treatment consistently upregulated $\mathrm{CDH} 1$ expression levels in both the MDA-MB-231 and MCF-7 cells; however, the MDA-MB231/E and MCF-7/E cells exhibited lower $\mathrm{CDH1}$ expression levels than their respective parental cell lines (Figure 6A).

We previously suggested that eribulin improves both immune responses to tumors, and the tumor microenvironment (8); thus, CD274 expression in the parental and eribulinresistant breast-cancer cells was also examined. Interestingly, the $C D 274$ expression levels in the MDA-MB-231/E cells were significantly lower than those in the MDA-MB-231 cells, while conversely, $C D 274$ expression levels were significantly higher in the MCF-7/E than in the MCF-7 cells (Figure 6B).

Eribulin-resistant tumor growth in vivo. MDA-MB-231 and MDA-MB-231/E subcutaneous xenografts were produced on the backs of nude mice, and the sizes of resulting tumors were measured weekly. The results of this analysis showed that the size of tumors produced using the eribulin-resistant breast-cancer cells was larger than that produced using parental breast-cancer cells (Figure 7A). The conducted immunohistochemical examination of the microenvironment in these tumors revealed no significant differences in the expression of programmed death-ligand 1 (PD-L1) between the MDA-MB-231 and MDA-MB-231/E-derived tumors (Figure 7B).

\section{Discussion}

Drug resistance is a major obstacle to the effective use of chemotherapy to treat breast cancer in the clinical setting. Recent studies have indicated that several anti-cancer agents induce EMT, and furthermore, EMT is associated with drug resistance (14-16). In contrast, current preclinical studies 

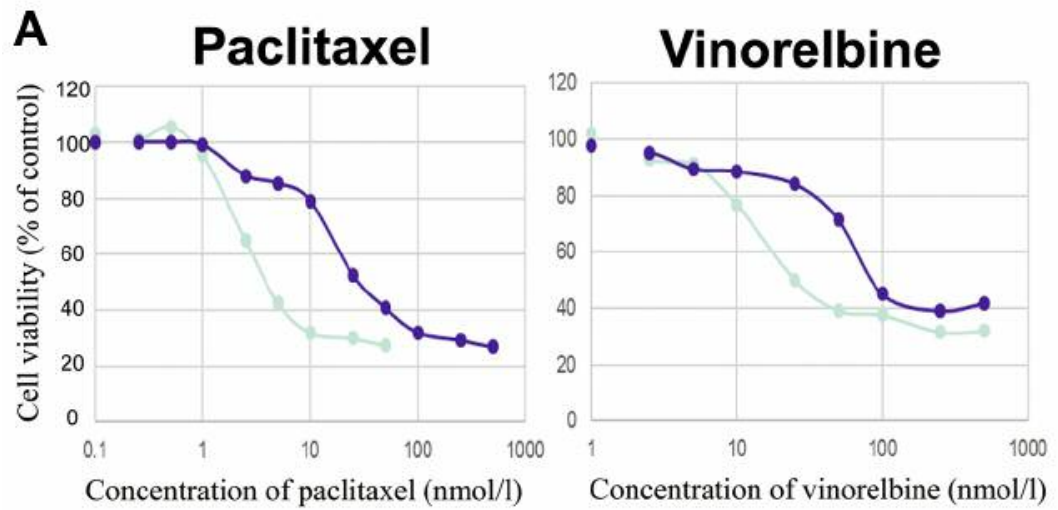

MDA-MB-231

- MDA-MB-231/E

E: eribulin-resistant

Gemcitabine

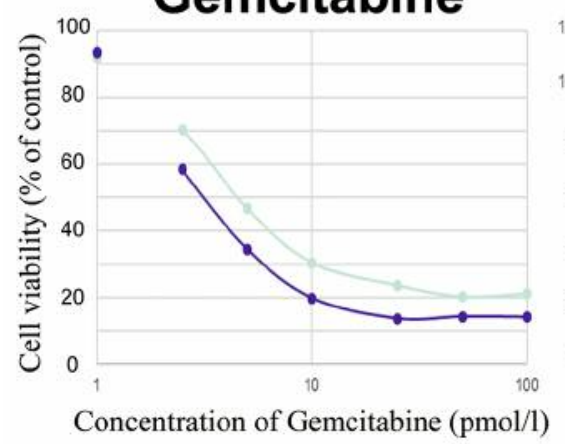

5-FU

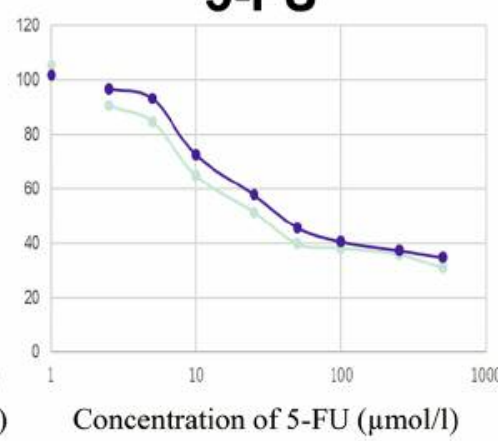

Cisplatin
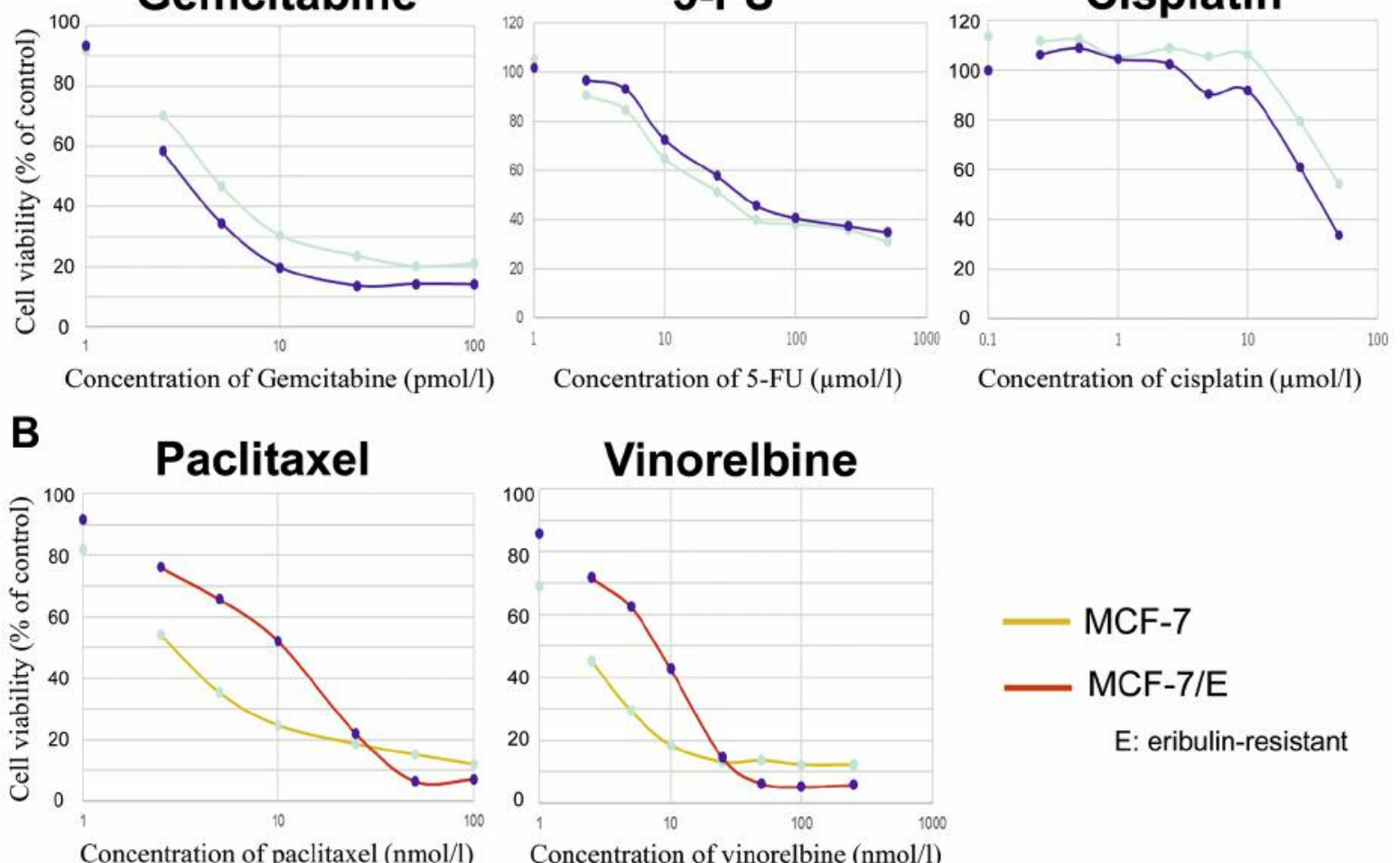

\section{Gemcitabine}
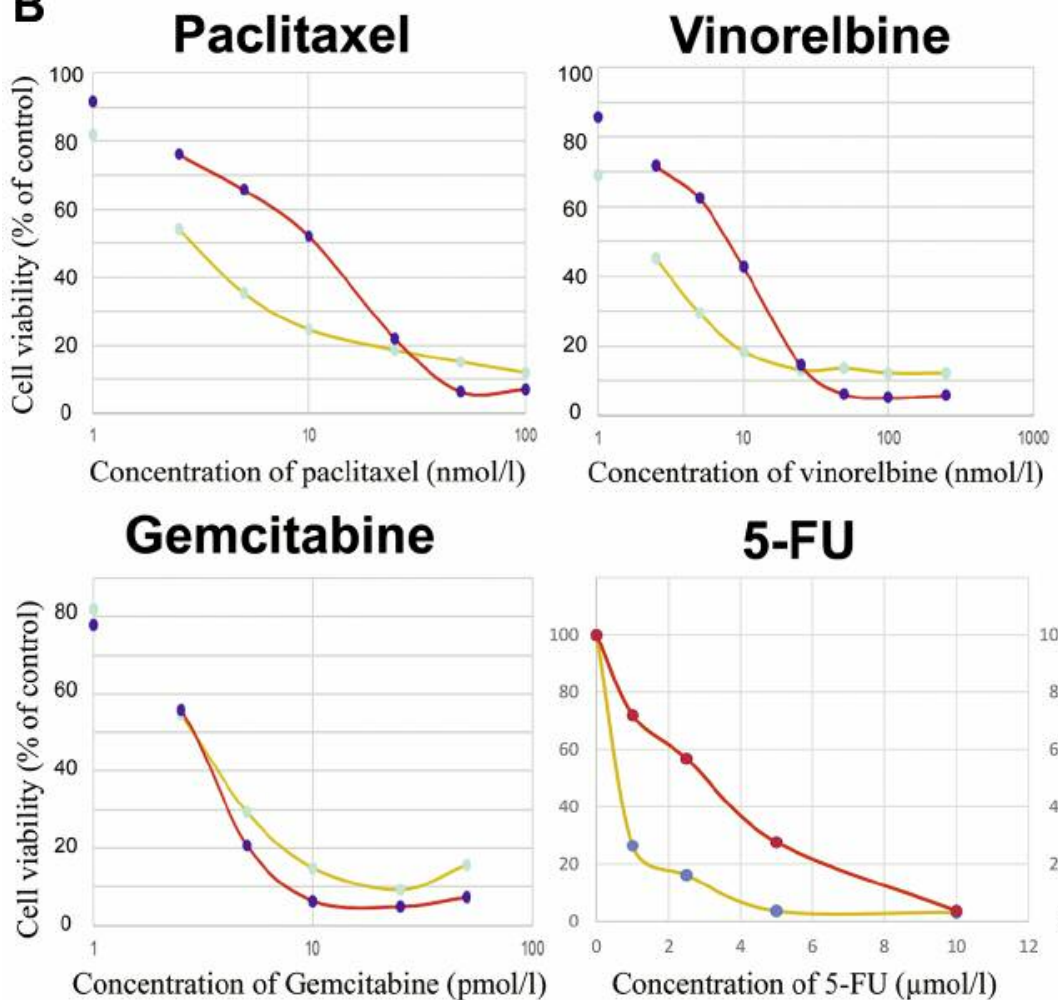

MCF-7

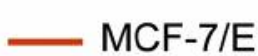

E: eribulin-resistant

5-FU

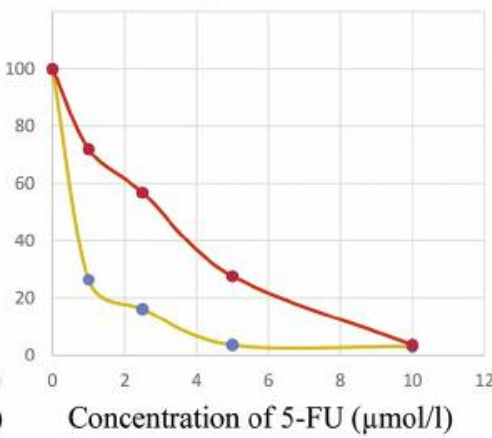

Cisplatin

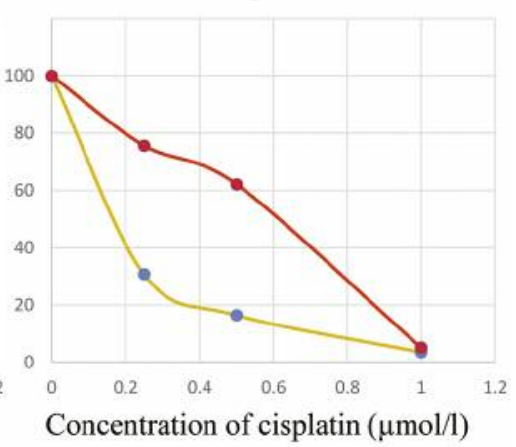

Figure 3. Dose-response curves of MDA-MB-231, MDA-MB-231/E (A) and MCF-7, MCF-7/E (B) to paclitaxel, vinorelbine, gemcitabine, 5-FU and $C D D P$. By analyzing the calculated dose-responsive curves and $I C_{50}$ values for these drugs, the MDA-MB-231/E cells were found to be crossresistant to PTX and VNB, but to remain sensitive to GEM, 5-FU, and CDDP. The MCF-7/E cells acquired cross-resistance to PTX, VNB, 5-FU, and CDDP, but retained their sensitivity to GEM. 


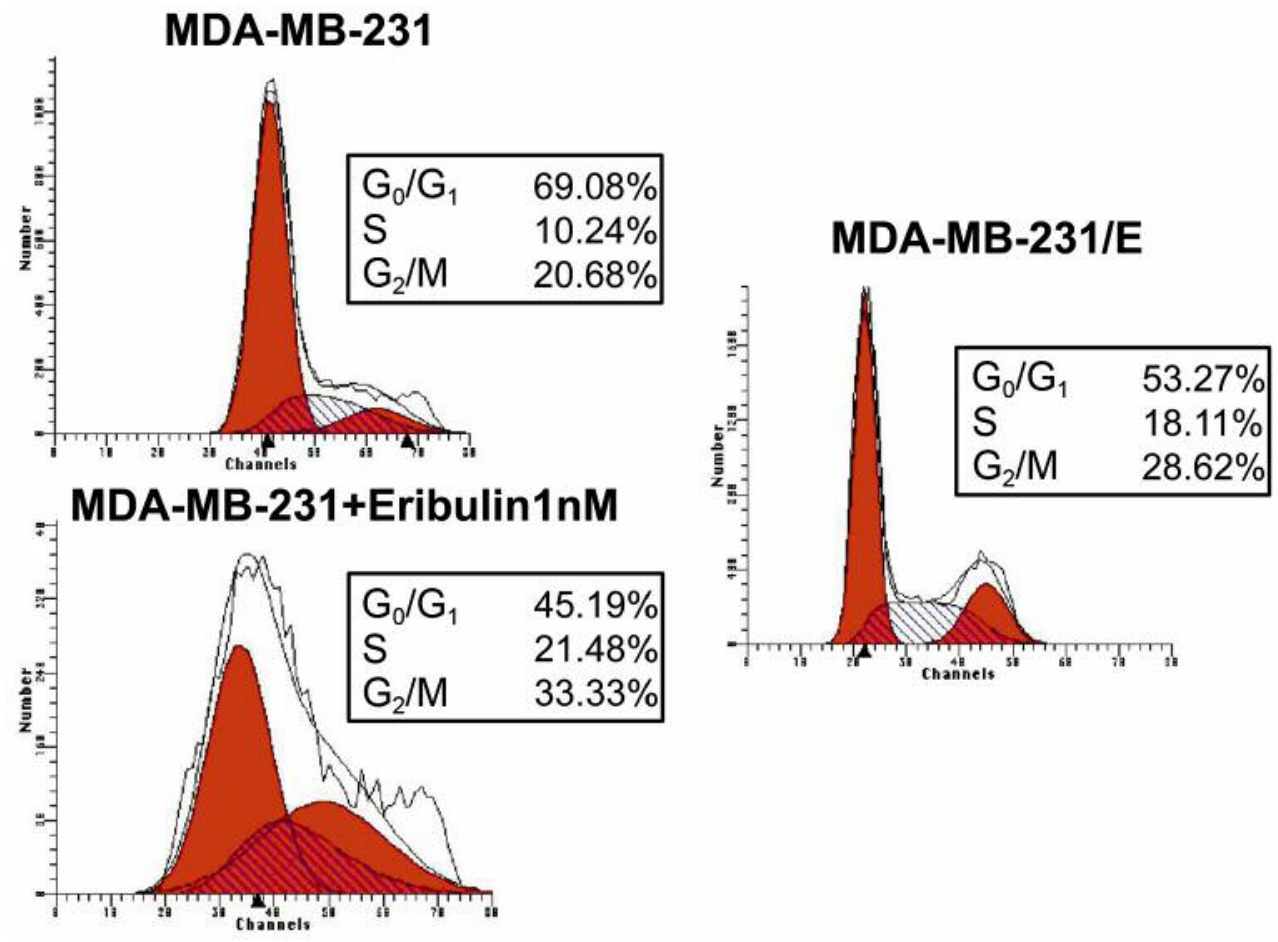

Figure 4. Cell-cycle analysis of MDA-MB-231, MDA+Eribulin10nM and MDA-MB-231/Eribulin. The results of this analysis showed that the percentage of MDA-MB-231 cells in $G_{2} / M$ and $G_{0} / G_{1}$ phases were significantly increased and decreased, respectively, after eribulin treatment. In contrast, the proportions of MDA-MB-231/E cells that were observed in each cell-cycle phase were not significantly altered after eribulin treatment. E: Eribulin-resistant.

suggest that eribulin reverses the EMT induced by TGF- $\beta$ or 5 -FU administration in triple-negative breast cancer (TNBC) $(6,17)$; thus, it is a promising drug to treat cancer cells with previously acquired chemotherapy resistance. Notably, the results of the present study suggest that this effect (i.e. EMT reversal) does not occur in eribulin-resistant breast-cancer cells.

In addition, the present study showed that the analyzed eribulin-resistant cell lines exhibited cross-resistance to other anticancer drugs. Previous studies have suggested that multiple-drug resistance is associated with the overexpression of a drug efflux pump (18); specifically, the ATP-binding cassette (ABC)-family proteins, including multi-drug resistance 1 (MDR1 or ABCB1), and the breast cancer resistance protein (BCRP), have been implicated as key efflux transporters that enable the development of multidrug resistance in breast cancer (19). Accordingly, Oba et al. demonstrated that $\mathrm{ABCB} 1$ and $\mathrm{ABCC} 11$ overexpression conferred eribulin resistance, as well as PTX, doxorubicin, and 5-FU cross-resistance to breast-cancer cells (13). In contrast, the MDA-MB-231/E cell line established by the present study did not acquire cross-resistance to GEM, 5-FU, nor CDDP, and similarly, the MCF-7/E cells did not acquire cross-resistance to GEM. Furthermore, the conducted western blot analysis showed that neither eribulin-resistant cell line exhibited MDR1 expression. Yahiro et al. previously reported no significant differences in P-glycoprotein (Pgp) protein levels between parental and eribulin-resistant leiomyosarcoma cell lines (20), and furthermore, previous studies have revealed that the combined treatment of $\mathrm{ABC}$ family proteins with inhibitors and cytotoxic drugs does not incur any significant improvement in patient outcomes compared to treatment with cytotoxic drugs alone $(21,22)$. Together, these results suggest that ABC family proteins may not play a dominant role in the acquisition of eribulin resistance, such as that observed in our established cell lines.

Eribulin binds specifically to the plus ends of microtubules, which are polymers composed of $\alpha$ - and $\beta$-tubulin (2). The present study showed that administering eribulin to the MDAMB-231 cells reduced EB1 levels and induced $G_{2} / M$ arrest; however, neither effect was induced by eribulin treatment in the MDA-MB-231/E cells. Interesting, the MDA-MB-231/E cells exhibited cross-resistance to PTX and VNB. While the binding sites and mechanisms utilized by PTX and VNB differ from those employed by eribulin, they are nevertheless considered to be anti-tubulin agents $(23,24)$. Consistent with this, previous studies have reported that alterations to the expression profiles of $\beta$-tubulin isotypes, particularly $\beta$-tubulin 


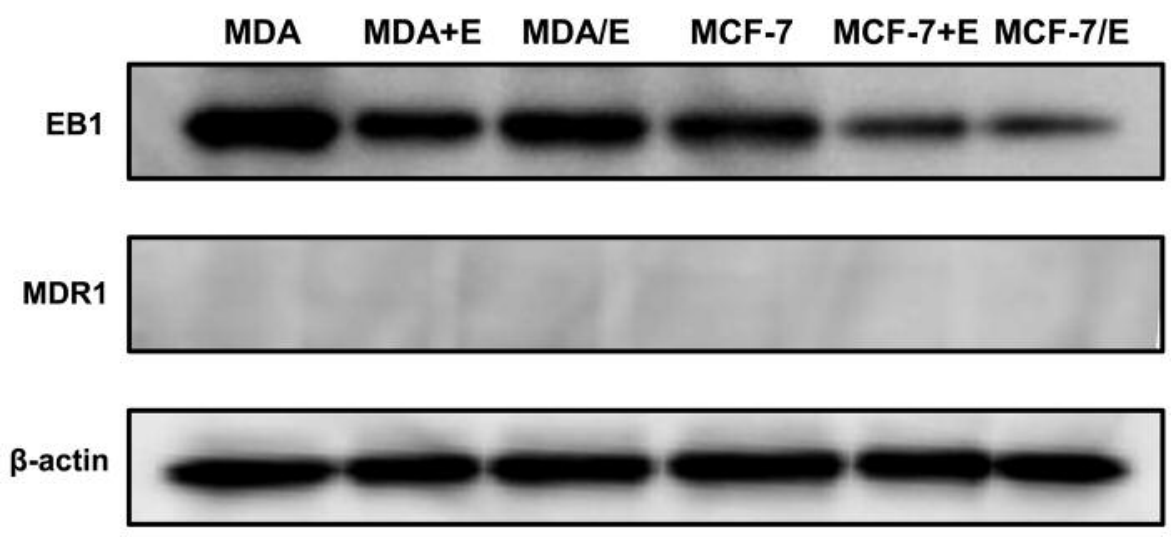

Figure 5. EB1 and MDR1 protein expression analysis. Although the expression of EB1 was decreased after eribulin treatment in the MDA-MB-231 cells, it was not altered by eribulin treatment in the MDA-MB-231/E cells. In contrast, EB1 expression was decreased in both the MCF-7 cells and $M C F-7 / E$ cells after eribulin treatment. E: Eribulin-resistant.

3 (TUBB3), are associated with the acquisition of resistance to microtubule inhibitors, such as PTX and VNB (25). Moreover, Wilson et al. showed that TUBB3 weakens the effects of eribulin (26), and similarly, TUBB3 overexpression has been implicated in the acquisition of eribulin-resistance in several cancers $(20,27)$. In the present study, continuous exposure to increasing concentrations of eribulin may have induced TUBB3 overexpression in the parental breast-cancer cell lines, and thereby facilitated eribulin-resistance acquisition; however, further research is needed to confirm this hypothesis.

To date, the impact of eribulin resistance-acquisition on the maintenance of immune checkpoints remains unknown. To the best of our knowledge, this is the first study to investigate $C D 274$ expression levels in eribulin-resistant breast-cancer cell lines. We previously reported that patients that responded to eribulin treatment were more likely to show decreased PD-L1 expression than those who did not (8); hence, we expected to observe PD-L1 overexpression in the established eribulin-resistant cell lines in the present study. However, the conducted qRT-PCR assay showed that the MDA-MB-231/E and MCF-7/E cell lines displayed significantly lower and higher CD274 expression than the parental cell lines, respectively. Notably, differences have been observed between the production of EB1 and the acquisition of cross-resistance in eribulin-resistant TNBC and luminal-type breast-cancer cell lines, suggesting that the mechanism underlying eribulin resistance-acquisition may differ in various breast-cancer subtypes. Further metabolomic analyses of specific eribulin-resistant cell lines is required to confirm this hypothesis, and elucidate the mechanisms involved.

Notably, the eribulin-resistant cells in the present study tended to grow more rapidly in vivo than the parental cells; however, unlike in the conducted in vitro experiments, no significant differences in PD-L1 expression were observed between tumors that were derived from the parental compared to the eribulin-resistant cells. Thus, the activity of eribulin-resistant cells in mice is anticipated to be associated with various mechanisms.

While many anticancer drugs have been recently developed to improve breast-cancer therapies, and thus, the prognosis of patients with recurrent or metastatic breast cancer (28), most breast-cancer cases acquire multidrug resistance after a series of treatments. Consistent with this finding, the herein established eribulin-resistant cell lines exhibited cross-resistance to other anti-tubulin agents. Recently, the cyclin-dependent kinase 4 and 6 (CDK4/6) inhibitors palbociclib and abemaciclib were shown to be clinically effective in treating breast cancer in patients with endocrine-therapy resistance (29-32). Given that CDK4/6 inhibitors are critical regulators of cell-cycle progression, it will be interesting to investigate whether they are effective against eribulin-resistant cancer cells, which the present study showed that they do not exhibit cell-cycle arrest. Further studies are necessary to unravel the complex mechanisms underlying eribulin-resistance acquisition, and to design strategies for the clinical treatment of eribulin- and mutli-drug-resistant breast-cancer cases.

\section{Conclusion}

We herein developed two eribulin-resistant breast-cancer cell lines to investigate the mechanisms that underlie drugresistance acquisition. We found that they acquired crossresistance to other anticancer agents, and resisted the antimicrotubule effect and EMT inhibition that is normally elicited by eribulin treatment. Furthermore, our findings also suggest that eribulin-resistant cells in some subtypes of breast 

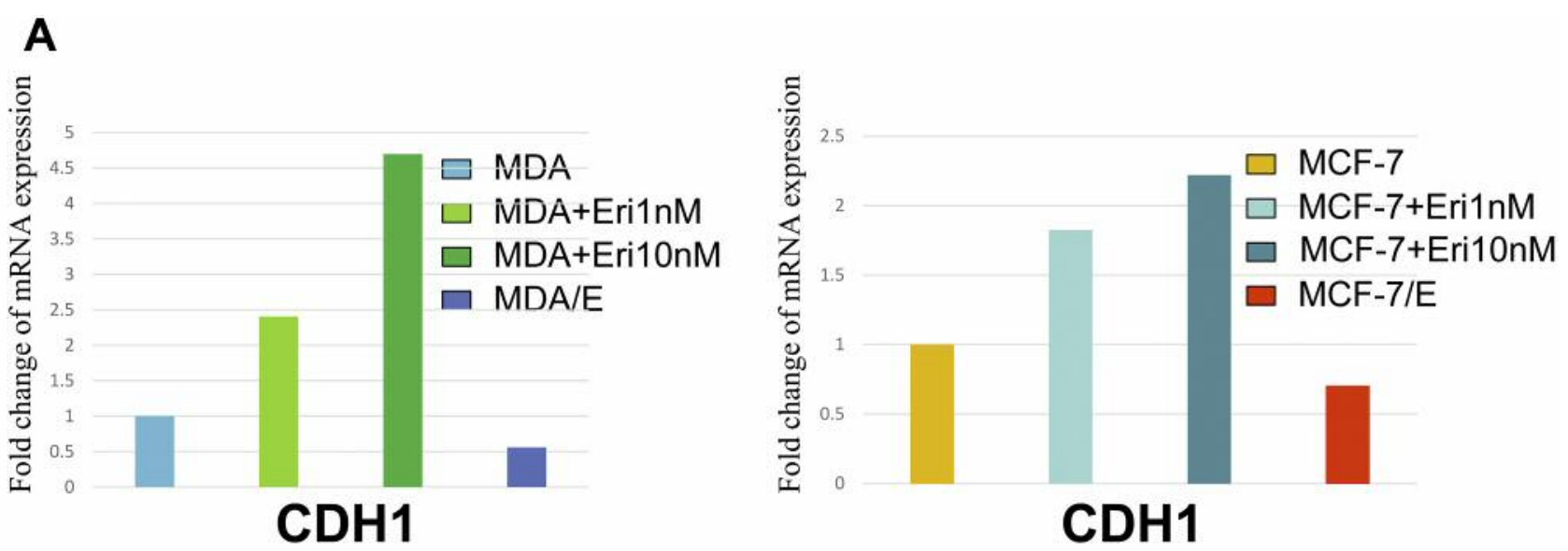

B
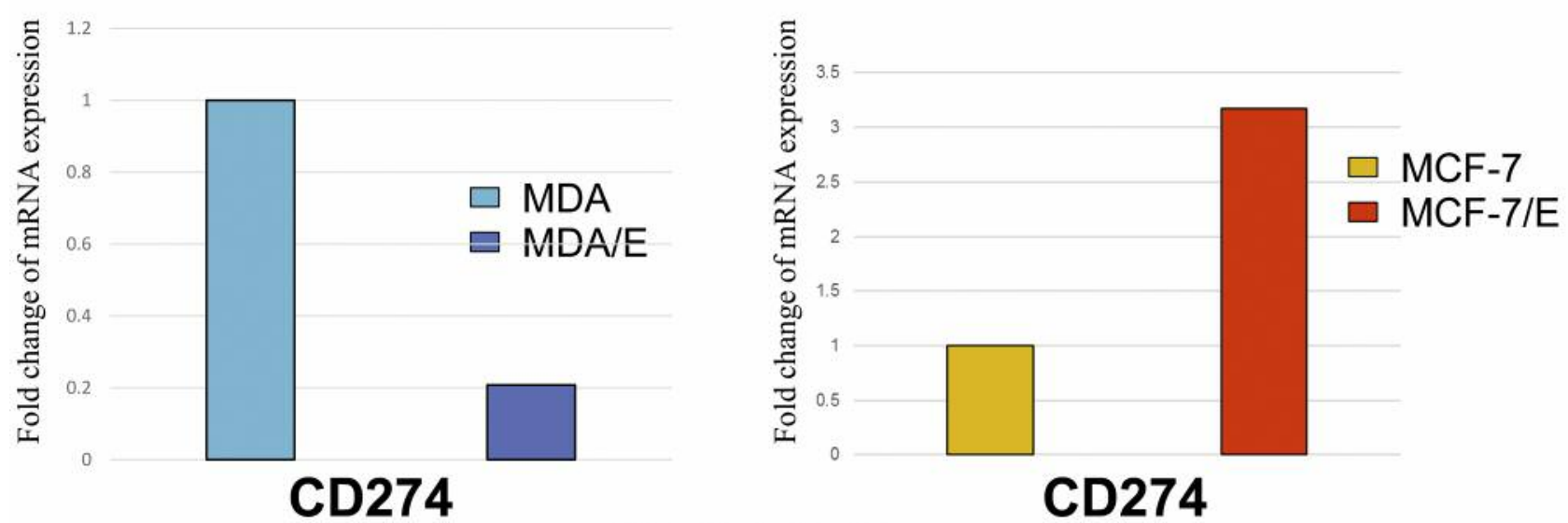

MDA: MDA-MB-231

E: eribulin-resistant

Figure 6. Expression levels of E-cadherin (A) and PD-L1 (B) mRNA in eribulin-treated MDA-MB-231, MDA-MB-231/E, MCF-7 and MCF-7/E cells as measured by RT-PCR. Eribulin treatment consistently up-regulated CDH1 expression levels in both the MDA-MB-231 and MCF-7 cells; however, the MDA-MB-231/E and MCF-7/E cells exhibited lower CDH1 expression levels than their respective parental cell lines. The CD274 expression levels in the MDA-MB-231/E cells were significantly lower than those in the MDA-MB-231 cells, while conversely, CD274 expression levels were significantly higher in the MCF-7/E than in the MCF-7 cells.

cancer may evade immune responses. Thus, the herein established eribulin-resistant cell lines will be useful tools for future studies aiming to identify novel mechanisms underlying the acquisition of eribulin-resistance in breast cancer.

\section{Conflicts of Interest}

All Authors have no conflicts of interest to disclose in regard to this study.

\section{Authors' Contributions}

All Authors were involved in the preparation of this manuscript. WG collected the data, and wrote the manuscript. SK, YA, KoT,
KaT, TT, MS and RA performed the operation and designed the study. WG, SK and ST summarized the data and revised the manuscript. $\mathrm{HF}, \mathrm{KH}$ and $\mathrm{MO}$ substantial contribution to the study design, performed the operation, and revised the manuscript. All Authors read and approved the final manuscript.

\section{Acknowledgements}

The Authors would like to thank Yayoi Matsukiyo and Tomomi Okawa (Department of Breast and Endocrine Surgery, Osaka City University Graduate School of Medicine) for helpful advice regarding data management. This study was supported in part by Grants-in Aid for Scientific Research (KAKENHI, Nos. 19K18046, 26461957, and 17K10559) from the Ministry of Education, Science, Sports, Culture and Technology of Japan. 
A 350
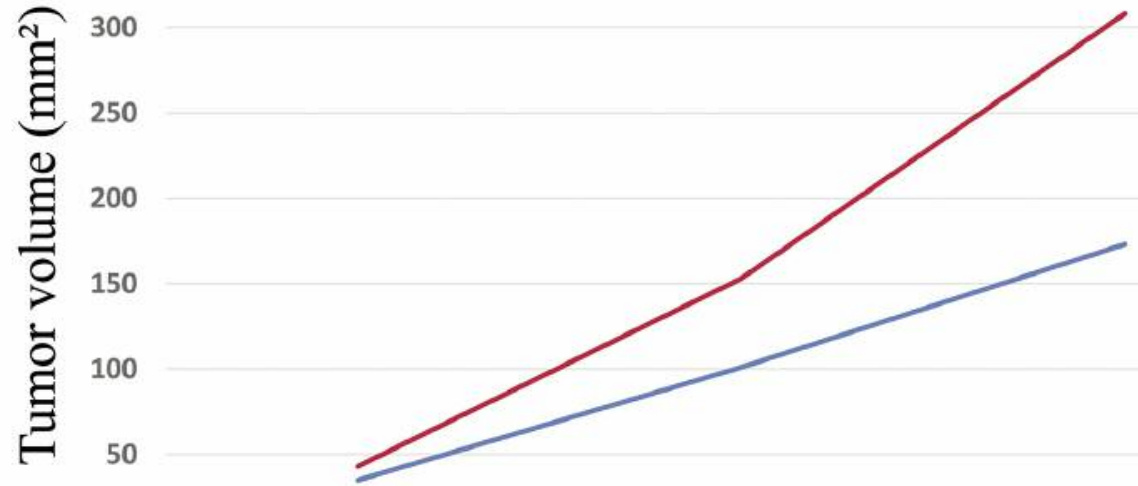

0

$1 \mathrm{~W}$ 2W

$3 W$

-MDA Xeno - MDA/E Xeno

MDA: MDA-MB-231

E: eribulin-resistant

Xeno: xenograft

\section{B}
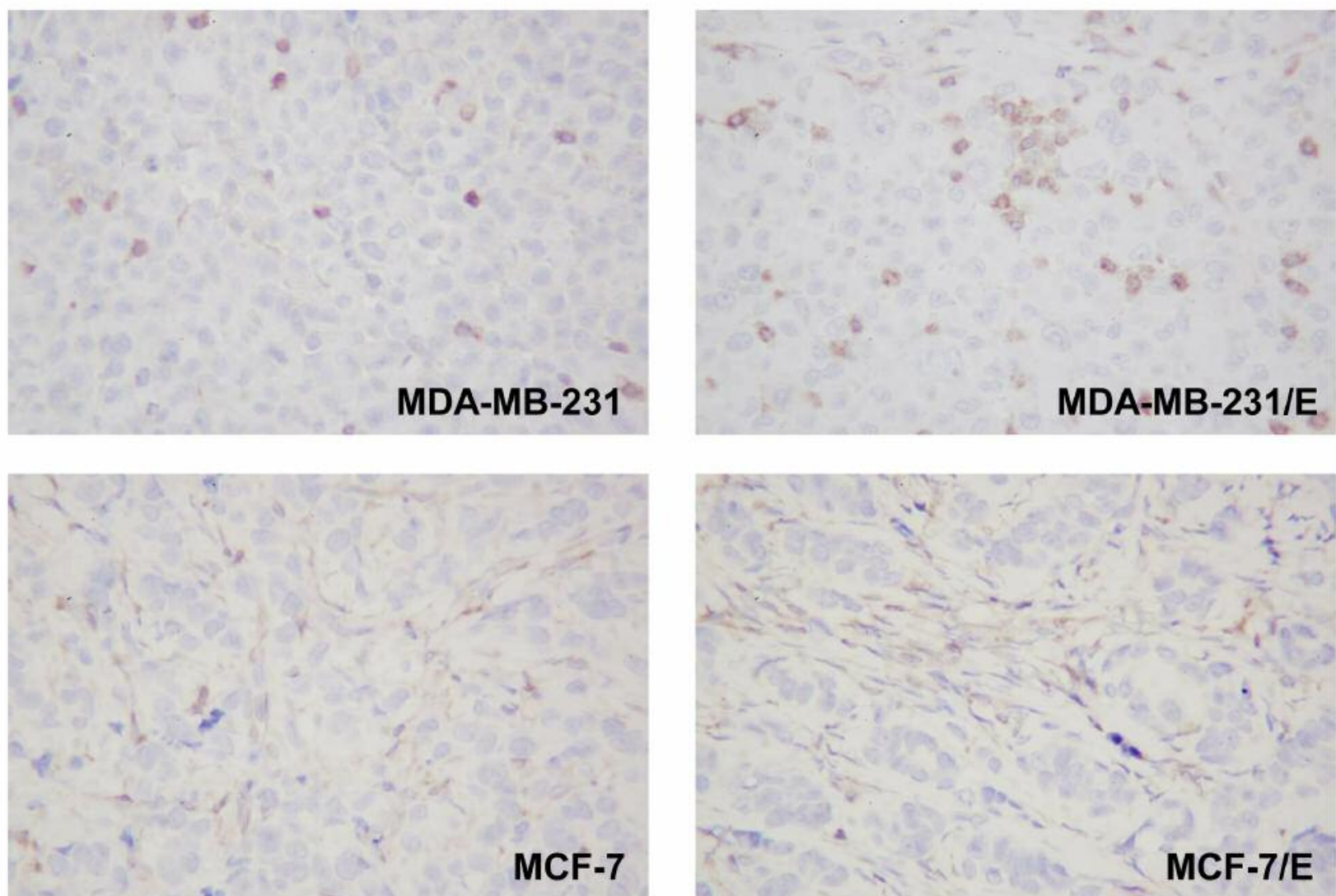

Figure 7. Tumor volumes of MDA-MB-231 and MDA-MB-231/E cells xenografts in mice (A). Immunostaining images of PD-L1 in MDA-MB-231, MDA$M B-231 / E, M C F-7$, and MCF-7/E cells xenografts in mice (B). The size of tumors produced using the eribulin-resistant breast-cancer cells was larger than that produced using parental breast-cancer cells $(A)$. The conducted immunohistochemical examination of the microenvironment in these tumors revealed no significant differences in the expression of PD-L1 between the MDA-MB-231 and MDA-MB-231/E-derived tumors (B). E: Eribulin-resistant. 


\section{References}

1 Towle MJ, Salvato KA, Budrow J, Wels BF, Kuznetsov G, Aalfs KK, Welsh S, Zheng W, Seletsky BM, Palme MH, Habgood GJ, Singer LA, Dipietro LV, Wang Y, Chen JJ, Quincy DA, Davis A, Yoshimatsu K, Kishi Y, Yu MJ and Littlefield BA: In vitro and in vivo anticancer activities of synthetic macrocyclic ketone analogues of halichondrin B. Cancer Res 61(3): 1013-1021, 2001. PMID: 11221827.

2 Kuznetsov G, Towle MJ, Cheng H, Kawamura T, TenDyke K, Liu D, Kishi Y, Yu MJ and Littlefield BA: Induction of morphological and biochemical apoptosis following prolonged mitotic blockage by halichondrin b macrocyclic ketone analog e7389. Cancer Res 64(16): 5760-5766, 2004. PMID: 15313917. DOI: 10.1158/0008-5472.CAN-04-1169

3 Jordan MA, Kamath K, Manna T, Okouneva T, Miller HP, Davis C, Littlefield BA and Wilson L: The primary antimitotic mechanism of action of the synthetic halichondrin e7389 is suppression of microtubule growth. Mol Cancer Ther 4(7): 1086-1095, 2005. PMID: 16020666. DOI: 10.1158/1535-7163.MCT-04-0345

4 Cortes J, O'Shaughnessy J, Loesch D, Blum JL, Vahdat LT, Petrakova K, Chollet P, Manikas A, Dieras V, Delozier T, Vladimirov V, Cardoso F, Koh H, Bougnoux P, Dutcus CE, Seegobin S, Mir D, Meneses N, Wanders J, Twelves C and investigators E: Eribulin monotherapy versus treatment of physician's choice in patients with metastatic breast cancer (embrace): A phase 3 open-label randomised study. Lancet 377(9769): 914-923, 2011. PMID: 21376385. DOI: 10.1016/ S0140-6736(11)60070-6

5 Funahashi Y, Okamoto K, Adachi Y, Semba T, Uesugi M, Ozawa Y, Tohyama O, Uehara T, Kimura T, Watanabe H, Asano M, Kawano S, Tizon X, McCracken PJ, Matsui J, Aoshima K, Nomoto $\mathrm{K}$ and Oda Y: Eribulin mesylate reduces tumor microenvironment abnormality by vascular remodeling in preclinical human breast cancer models. Cancer Sci 105(10): 1334-1342, 2014. PMID: 25060424. DOI: 10.1111/cas.12488

6 Yoshida T, Ozawa Y, Kimura T, Sato Y, Kuznetsov G, Xu S, Uesugi M, Agoulnik S, Taylor N, Funahashi Y and Matsui J: Eribulin mesilate suppresses experimental metastasis of breast cancer cells by reversing phenotype from epithelialmesenchymal transition (emt) to mesenchymal-epithelial transition (met) states. Br J Cancer 110(6): 1497-1505, 2014. PMID: 24569463. DOI: 10.1038/bjc.2014.80

7 Kashiwagi S, Asano Y, Goto W, Takada K, Takahashi K, Hatano T, Tanaka S, Takashima T, Tomita S, Motomura H, Ohsawa M, Hirakawa $\mathrm{K}$ and Ohira M: Mesenchymal-epithelial transition and tumor vascular remodeling in eribulin chemotherapy for breast cancer. Anticancer Res 38(1): 401-410, 2018. PMID: 29277801. DOI: 10.21873 /anticanres.12236

8 Goto W, Kashiwagi S, Asano Y, Takada K, Morisaki T, Fujita H, Takashima T, Ohsawa M, Hirakawa K and Ohira M: Eribulin promotes antitumor immune responses in patients with locally advanced or metastatic breast cancer. Anticancer Res 38(5): 2929-2938, 2018. PMID: 29715119. DOI: 10.21873/anticanres. 12541

9 Doublier S, Belisario DC, Polimeni M, Annaratone L, Riganti C, Allia E, Ghigo D, Bosia A and Sapino A: Hif-1 activation induces doxorubicin resistance in mcf7 3-d spheroids via p-glycoprotein expression: A potential model of the chemo-resistance of invasive micropapillary carcinoma of the breast. BMC Cancer 12: 4, 2012. PMID: 22217342. DOI: 10.1186/ 1471-2407-12-4
10 Kajiyama H, Shibata K, Terauchi M, Yamashita M, Ino K, Nawa $\mathrm{A}$ and Kikkawa F: Chemoresistance to paclitaxel induces epithelial-mesenchymal transition and enhances metastatic potential for epithelial ovarian carcinoma cells. Int J Oncol 31(2): 277-283, 2007. PMID: 17611683.

11 Zhang X, Yashiro M, Qiu H, Nishii T, Matsuzaki T and Hirakawa K: Establishment and characterization of multidrugresistant gastric cancer cell lines. Anticancer Res 30(3): 915-921, 2010. PMID: 20393015

12 Takahashi K, Tanaka M, Inagaki A, Wanibuchi H, Izumi Y, Miura K, Nagayama K, Shiota M and Iwao H: Establishment of a 5-fluorouracil-resistant triple-negative breast cancer cell line. Int J Oncol 43(6): 1985-1991, 2013. PMID: 24126575. DOI: 10.3892/ijo.2013.2135

13 Oba T, Izumi H and Ito KI: Abcb1 and abcc11 confer resistance to eribulin in breast cancer cell lines. Oncotarget 7(43): 7001170027, 2016. PMID: 27588398. DOI: 10.18632/oncotarget. 11727

14 Frederick BA, Helfrich BA, Coldren CD, Zheng D, Chan D, Bunn PA, Jr. and Raben D: Epithelial to mesenchymal transition predicts gefitinib resistance in cell lines of head and neck squamous cell carcinoma and non-small cell lung carcinoma. Mol Cancer Ther 6(6): 1683-1691, 2007. PMID: 17541031. DOI: 10.1158/1535-7163.MCT-07-0138

15 Arumugam T, Ramachandran V, Fournier KF, Wang H, Marquis L, Abbruzzese JL, Gallick GE, Logsdon CD, McConkey DJ and Choi W: Epithelial to mesenchymal transition contributes to drug resistance in pancreatic cancer. Cancer Res 69(14): 5820-5828, 2009. PMID: 19584296. DOI: 10.1158/0008-5472.CAN-08-2819

16 Wang Z, Li Y, Kong D, Banerjee S, Ahmad A, Azmi AS, Ali S, Abbruzzese JL, Gallick GE and Sarkar FH: Acquisition of epithelial-mesenchymal transition phenotype of gemcitabineresistant pancreatic cancer cells is linked with activation of the notch signaling pathway. Cancer Res 69(6): 2400-2407, 2009. PMID: 19276344. DOI: 10.1158/0008-5472.CAN-08-4312

17 Terashima M, Sakai K, Togashi Y, Hayashi H, De Velasco MA, Tsurutani J and Nishio K: Synergistic antitumor effects of s-1 with eribulin in vitro and in vivo for triple-negative breast cancer cell lines. Springerplus 3: 417, 2014. PMID: 25140293. DOI: 10.1186/2193-1801-3-417

18 Holohan C, Van Schaeybroeck S, Longley DB and Johnston PG: Cancer drug resistance: An evolving paradigm. Nat Rev Cancer 13(10): 714-726, 2013. PMID: 24060863. DOI: 10.1038/nrc3599

19 Baguley BC: Multiple drug resistance mechanisms in cancer. Mol Biotechnol 46(3): 308-316, 2010. PMID: 20717753. DOI: 10.1007/s12033-010-9321-2

20 Yahiro K, Matsumoto Y, Fukushi JI, Kawaguchi KI, Endo M, Setsu N, K II, Fukushima S, Nakagawa M, Kimura A, Oda Y and Nakashima Y: Class iii beta-tubulin overexpression induces chemoresistance to eribulin in a leiomyosarcoma cell line. Anal Cell Pathol (Amst) 2018: 8987568, 2018. PMID: 30034996. DOI: $10.1155 / 2018 / 8987568$

21 Ruff P, Vorobiof DA, Jordaan JP, Demetriou GS, Moodley SD, Nosworthy AL, Werner ID, Raats $\mathrm{J}$ and Burgess LJ: A randomized, placebo-controlled, double-blind phase 2 study of docetaxel compared to docetaxel plus zosuquidar (ly335979) in women with metastatic or locally recurrent breast cancer who have received one prior chemotherapy regimen. Cancer Chemother Pharmacol 64(4): 763-768, 2009. PMID: 19241078. DOI: $10.1007 / \mathrm{s} 00280-009-0925-9$ 
22 Abraham J, Edgerly M, Wilson R, Chen C, Rutt A, Bakke S, Robey R, Dwyer A, Goldspiel B, Balis F, Van Tellingen O, Bates SE and Fojo T: A phase i study of the p-glycoprotein antagonist tariquidar in combination with vinorelbine. Clin Cancer Res 15(10): 3574-3582, 2009. PMID: 19417029. DOI: 10.1158/ 1078-0432.CCR-08-0938

23 Bedard PL, Di Leo A and Piccart-Gebhart MJ: Taxanes: Optimizing adjuvant chemotherapy for early-stage breast cancer. Nat Rev Clin Oncol 7(1): 22-36, 2010. PMID: 19997076. DOI: 10.1038/nrclinonc.2009.186

24 Panda D, Jordan MA, Chu KC and Wilson L: Differential effects of vinblastine on polymerization and dynamics at opposite microtubule ends. J Biol Chem 271(47): 29807-29812, 1996. PMID: 8939919. DOI: 10.1074/jbc.271.47.29807

25 Seve P and Dumontet C: Is class iii beta-tubulin a predictive factor in patients receiving tubulin-binding agents? Lancet Oncol 9(2): 168-175, 2008. PMID: 8939919. DOI: 10.1074/jbc.271 47.29807

26 Wilson L, Lopus M, Miller HP, Azarenko O, Riffle S, Smith JA and Jordan MA: Effects of eribulin on microtubule binding and dynamic instability are strengthened in the absence of the betaiii tubulin isotype. Biochemistry 54(42): 6482-6489, 2015. PMID: 26435331. DOI: $10.1021 /$ acs.biochem.5b00745

27 Sampson VB, Vetter NS, Zhang W, Patil PU, Mason RW, George E, Gorlick R and Kolb EA: Integrating mechanisms of response and resistance against the tubulin binding agent eribulin in preclinical models of osteosarcoma. Oncotarget 7(52): 8659486607, 2016. PMID: 27863409. DOI: 10.18632/oncotarget. 13358

28 Giordano SH, Buzdar AU, Smith TL, Kau SW, Yang Y and Hortobagyi GN: Is breast cancer survival improving? Cancer 100(1): 44-52, 2004. PMID: 14692023
29 Finn RS, Martin M, Rugo HS, Jones S, Im SA, Gelmon K, Harbeck N, Lipatov ON, Walshe JM, Moulder S, Gauthier E, Lu DR, Randolph S, Dieras V and Slamon DJ: Palbociclib and letrozole in advanced breast cancer. N Engl J Med 375(20): 1925-1936, 2016. PMID: 27959613

30 Turner NC, Ro J, Andre F, Loi S, Verma S, Iwata H, Harbeck N, Loibl S, Huang Bartlett C, Zhang K, Giorgetti C, Randolph S, Koehler M, Cristofanilli $M$ and Group PS: Palbociclib in hormone-receptor-positive advanced breast cancer. N Engl J Med 373(3): 209-219, 2015. PMID: 26030518

31 Sledge GW Jr., Toi M, Neven P, Sohn J, Inoue K, Pivot X, Burdaeva O, Okera M, Masuda N, Kaufman PA, Koh H, Grischke EM, Frenzel M, Lin Y, Barriga S, Smith IC, Bourayou $\mathrm{N}$ and Llombart-Cussac A: Monarch 2: Abemaciclib in combination with fulvestrant in women with $\mathrm{hr}+/$ her2- advanced breast cancer who had progressed while receiving endocrine therapy. J Clin Oncol 35(25): 2875-2884, 2017. PMID: 28580882. DOI: $10.1200 / J C O .2017 .73 .7585$

32 Goetz MP, Toi M, Campone M, Sohn J, Paluch-Shimon S, Huober J, Park IH, Tredan O, Chen SC, Manso L, Freedman OC, Garnica Jaliffe G, Forrester T, Frenzel M, Barriga S, Smith IC, Bourayou N and Di Leo A: Monarch 3: Abemaciclib as initial therapy for advanced breast cancer. J Clin Oncol 35(32): 3638-3646, 2017. PMID: 28968163.

Received May 23, 2019

Revised June 11, 2019

Accepted June 12, 2019 